\title{
Simple Modeling of Crystal Structure of Carbon Tetrachloride, Diamond, and Fullerene using Molymods
}

\author{
Himawan Putranta ${ }^{1}$, Heru Kuswanto ${ }^{2}$, Wipsar Sunu Brams Dwandaru ${ }^{2}$, \\ Hery Setiyatna ${ }^{3}$, Syella Ayunisa Rani ${ }^{1}$, Aditya Yoga Purnama ${ }^{1}$ \\ ${ }^{1}$ Concentration of Physics Education, Department of Educational Sciences, Graduate School, Universitas \\ Negeri Yogyakarta, Yogyakarta 55281, Indonesia \\ ${ }^{2}$ Department of Physics Education, Faculty of Mathematics and Natural Sciences, Universitas Negeri \\ Yogyakarta, Yogyakarta 55281, Indonesia \\ ${ }^{3}$ Concentration of Educational Research and Evaluation, Faculty of Tarbiyah Sciences, Institut Agama Islam \\ Negeri Surakarta, Surakarta 57168, Indonesia
}

\begin{abstract}
This research aims to make simple modeling of the crystal structure of carbon tetrachloride, diamond, and fullerenes using molymod. The method used is a descriptive quantitative with the research stages including the selection, making, and testing the feasibility of crystal structure. The feasibility of the crystal structure was assessed using a product feasibility test sheet and analyzed using the ideal standard mean equation. The development of a crystal structure model was carried out using a simple and easy method to obtain equipment in the form of molymod. The results of this research indicate that the crystal structure of carbon tetrachloride, diamond, and fullerenes can be interpreted significantly and easily with the help of molymod. The simple model of the crystal structure is also suitable for use as a physics learning medium that can help students understand abstract crystal structure material.
\end{abstract}

Keywords - Carbon tetrachloride, crystal structure, diamonds, fullerenes, modeling, molymod.

DOI: $10.18421 /$ TEM102-50

https://doi.org/10.18421/TEM102-50

Corresponding author: Himawan Putranta,

Concentration of Physics Education, Department of Educational Sciences, Graduate School, Universitas Negeri Yogyakarta, Yogyakarta 55281, Indonesia.

Email: himawanputranta.2020@student.uny.ac.id

Received: 16 November 2020.

Revised: 22 April 2021.

Accepted: 28 April 2021.

Published: 27 May 2021.

(c))BY-NC-ND (C) 2021 Himawan Putranta et al; published by UIKTEN. This work is licensed under the Creative Commons Attribution-NonCommercial-NoDerivs 4.0 License.

The article is published with Open Access at www.temjournal.com

\section{Introduction}

In facing the challenges of the industrial revolution 4.0 and the 21 st century, teacher and student need to be equipped in their spirit to continue to innovate in developing physics science. This is intended so that quality of physics learning can continue to increase and create a person who excels in mastering physics and technology materials that are integrated with existing cultural values. Moreover, physics is a branch of natural science that reveals every physical phenomenon that exists in everyday life, both physical symptoms caused by nature itself or those produced by humans [1]. Therefore, physics teachers and students need to collaborate to mutually express every physical symptom that appears in life practically and understandably. In expressing physical symptoms that appear in life, teachers should use learning media that are simple, easy to use, and easy for students to understand in depth. One form of interpreting physical symptoms so that students can easily understand them is through modeling with the help of simple equipment [2]. However, students need to be given the freedom to construct modeling of symptoms or physical concepts so that they can interpret what they are learning.

The majority of physics material modeling in schools is in the form of a set of teaching aids to help model abstract physics material [3]. The teaching aids kit, especially the physics material modeling kit, is usually only owned by schools in big cities, while schools in remote areas are difficult to have. However, the majority of student activities in remote areas are very dependent on the nature they live in and still hold tightly to cultural values so that they can interpret the physical material they learn through cultural approaches or natural activities [4]. This is what students who live in urban areas do not have. 
Besides, with easy access to technology and information from the outside world, physics teachers should be able to overcome existing limitations in their schools through various physics learning initiatives. Even though a physics modeling kit is not owned by schools in remote areas, physics teachers should also be able to outsmart it by innovating using simple, accessible, and easy tools to model physics material.

Through the development of physics material modeling, it can make it easier for teachers to teach physics material to students so that they can be helped in understanding the physics material [5]. Besides, with the development of physics material modeling, it can also provide various choices of learning media that can be used by teachers when teaching physics material to their students. Furthermore, apart from using a physics modeling kit that is difficult to reach, modeling of physics material can also be done using simple tools that are easily available to anyone, one of which uses the help of molymod [6]. This is also supported by the results of research which reveals that modeling of physics classes using molymod's assistance can make it easier for students to study physics material, especially crystal structures that are abstract [7]. Molymod is also a learning medium that can increase the creativity and innovation abilities of students in modeling physics courses [8]. Thus, the existence of abstract modeling of physics material, one of which is about the crystal structure, is needed in the physics learning process.

Molymod is a simple tool used to model a molecule or crystal structure [9]. Even though some are made of wood, most molymods on the market are made of plastic. Molymod consists of dots and small plastic rods. This molecule can be used to model crystal structures in the form of tetrahedral, hexagonal, or planar forms [10]. However, modeling using molymod is still rarely done by teachers in schools, even though modeling using molymod is easy to do and can increase the creativity of students [11]. Modeling using molymod can also be used to model various types of crystal structures such as precious crystals in the world, namely diamonds [12]. Therefore, with the variety of crystal structures that can be modeled using the help of molymod and the rarity of modeling using molymod, there is a need for innovation in the development of physics learning media in the form of molymod-assisted crystal structure modeling. The crystal structure modeled with the help of molymod in this research is the crystal structure of carbon tetrachloride, diamond, and fullerenes.
The crystal structure that is modeled using molymod assistance is in the form of carbon tetrachloride, diamond, and fullerenes because the three crystal structures have different shapes. Through the modeling of crystal structures with different shapes, students are expected to be able to know more about the characteristics of each crystal form and its life benefits. The three crystals are used because they are crystals composed of carbon atoms from simple to complex [13]. Besides, the selection of the three crystal structures was also carried out because the three crystal structures are basic crystal structures that form more complex crystal structures [14].

In general, the crystal structure of carbon tetrachloride is tetrahedral with the chemical formula $\mathrm{CCl}_{4}$. These carbon tetrachloride crystals are often used in organic chemical synthesis, fire extinguishing, and refrigeration. At room temperature, carbon tetrachloride is a colourless liquid with a sweet odour. The shape of a tetrahedral crystal is like the form of a carbon crystal that binds to four chlorine atoms which is one of the basic forms of a more complex crystal structure [15]. The crystals are formed from the combination of a tetrahedral crystal structure, namely a diamond. Diamond is a crystal with a more complex tetrahedral combination than the crystal structure of carbon tetrachloride. In general, carbon with atomic number six has two and four-electron configurations. This means that there are four electrons in the outer shell of the carbon atom and when forming a diamond structure, these four electrons are used to form four single covalent bonds with four other carbon atoms. Therefore, the diamond has a very high melting point which is around $4000^{\circ} \mathrm{C}$. This is caused by the covalent bonds between the carbon constituents which are very strong and will only be broken when the diamond crystals are heated to their melting point [16].

Fullerenes are also crystals composed of carbon tetrahedral bonds. Fullerenes are a carbon molecule consisting of sixty carbon atoms so it is often referred to as $\mathrm{C}_{60}$. In the structure of the fullerene, each carbon atom bonds to three other carbon atoms in a pentagonal arrangement to form a hollow balllike structure in a football game. Fullerenes are not only hollow spherical, but also have a cylindrical shape which is often referred to as carbon nanotubes [17]. Based on the problems described above, this research will develop simple modelling of the crystal structure of carbon tetrachloride, diamond, and fullerenes assisted by molymod. The development of a molymod-assisted crystal structure model is intended to create a crystal structure model that has never been made by researchers before using simple and accessible tools for everyone. 


\section{Methods}

This research is quantitative descriptive research with the stages including the stage of selecting, making crystal structures, and testing the feasibility of crystal structures as innovative physics learning media. The first step in this research is to select the crystal structure that will be modeled with the help of molymod. The topic of the crystal structure chosen to be modeled with the help of molymod is the crystal structure of carbon atoms consisting of carbon tetrachloride, diamond, and fullerenes. The reasons for choosing the three crystal structures have been explained in the previous section, but the main reason for selecting the three crystal structures is because the three crystal structures are composed of carbon atoms from the simplest to the most complex [18]. Therefore, the structure of the three crystals may be interconnected and make it easier for students to identify similarities and differences.

The next step is to find a reference source for modeling physical symptoms, especially crystal structures using the help of molymod by fixing the limitations of the modeling that has been constructed by previous researchers. The next step is to design the structural design of the three crystals that have been selected. The design of the three crystal structures modeled through the help of molymod is shown in Figure 1 below.

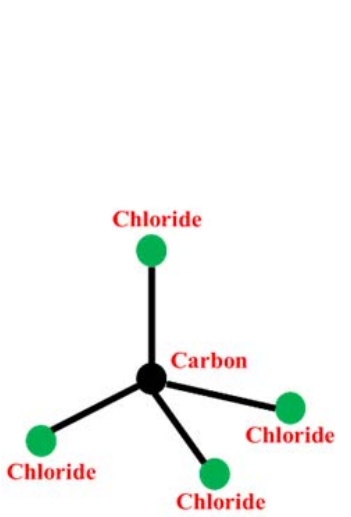

(a)

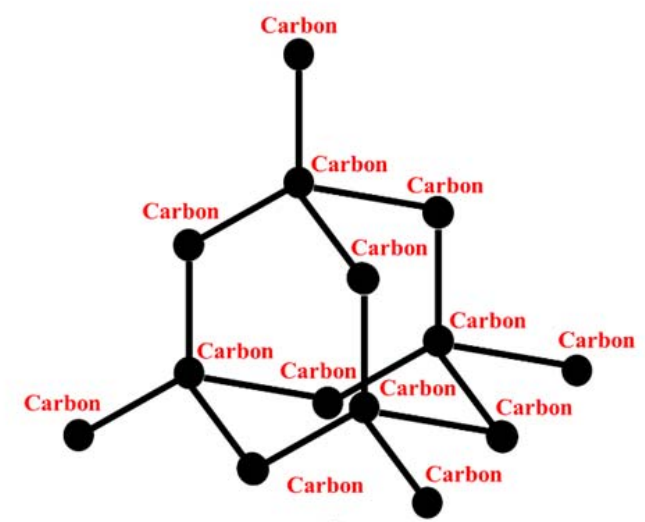

(b)

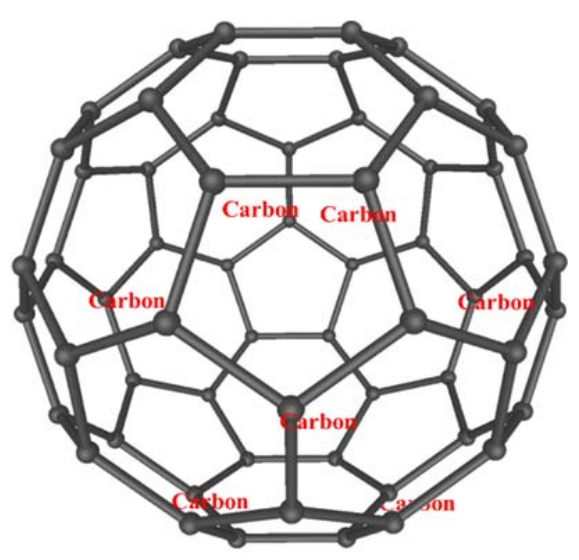

(c)

Figure 1. Design of crystal structure, (a) carbon tetrachloride, (b) diamond, and (c) fullerenes

The second stage is to construct the modeling of the crystal structure of carbon tetrachloride, diamond, and fullerenes using the help of molymod based on the design shown in Figure 1. The initial step is to prepare the equipment in the form of a molymod set and the mold results of the crystal structure design of carbon tetrachloride, diamond, and fullerenes as shown in Figure 1. Molymod used in this modeling consists of round and cylindrical shapes. After all the equipment has been prepared, the next step is to take 60 molymods which are round and cylindrical each. The next step is to construct a carbon tetrachloride crystal structure according to the design image shown in Figure 1(a). The step begins by taking fiveround molymods with details of four green and one black, and four cylindrical molymods. The next step is to connect the selected molymod according to the design of the carbon tetrachloride crystal structure as shown in Figure 1(a).

After the carbon tetrachloride crystal structure is formed, the next step is to construct the crystal structure modeling for diamond and fullerenes. The steps taken in constructing the modeling of the diamond crystal structure were taking thirteen black, round molymods, and sixteen cylindrical molymods. The next step is to connect the selected molymod according to the diamond structural design as shown in Figure 1(b). Meanwhile, the steps taken in constructing the fullerenes crystal structure modeling were taking sixty black molymods and sixty-two cylindrical molymods. The next step is to connect the selected molymod according to the fullerenes structural design as shown in Figure 1(c).

After the three crystal structures can be modelled with the help of molymod, the third step is to test the feasibility of the crystal structure model. This feasibility test was carried out to determine the feasibility of the third model of crystal structure assisted by molymod as an innovative physics learning medium. This feasibility testing phase was carried out by six experts consisting of two media expert lecturers, two material expert lecturers, and two physics teachers. The instrument used to assess the feasibility of the three crystal structure models used a feasibility assessment questionnaire with yes and no answer choices. Aspects that are assessed for feasibility include aspects of learning, material, appearance, and aspects of innovation. Meanwhile, the detailed assessment indicators for the feasibility of modeling the crystal structure of carbon tetrachloride, diamond, and fullerenes as innovative physics learning media is shown in Table 1 . 
Table 1. Feasibility Indicators of Crystal Structure Modelling

\begin{tabular}{|c|c|c|}
\hline No. & Aspect & Indicator \\
\hline 1. & Learning & $\begin{array}{l}\text { 1. The suitability of the crystal } \\
\text { structure model with the } \\
\text { learning objectives. } \\
\text { 2. Clarity of learning instructions } \\
\text { in the crystal structure model. } \\
\text { 3. The suitability of the delivery of } \\
\text { the material presented in the } \\
\text { crystal structure model with the } \\
\text { principles of learning. } \\
\text { 4. The suitability of the given } \\
\text { crystal structure model with the } \\
\text { learning material. } \\
\text { 5. The suitability of the given } \\
\text { crystal structure model with the } \\
\text { personal abilities of students. }\end{array}$ \\
\hline 2. & Materials & $\begin{array}{l}\text { 1. The effectiveness of explaining } \\
\text { the learning material using a } \\
\text { crystal structure model. } \\
\text { 2. The logical explanation of } \\
\text { learning materials with a crystal } \\
\text { structure model. } \\
\text { 3. Clarity of the concept of } \\
\text { material with the accuracy of the } \\
\text { application of the material to the } \\
\text { crystal structure model. } \\
\text { 4. The conciseness of the material } \\
\text { explanation. } \\
\text { 5. The accuracy of choosing } \\
\text { climates in explaining the } \\
\text { material using a crystal structure } \\
\text { model. }\end{array}$ \\
\hline 3. & Display & $\begin{array}{l}\text { 1. The suitability of the colour } \\
\text { selection between the crystal } \\
\text { structure model and the design. } \\
\text { 2. The conformity of the crystal } \\
\text { structure model with the design. } \\
\text { 3. Completeness of components } \\
\text { between the crystal structure } \\
\text { model with the design. } \\
\text { 4. The symmetry of the crystal } \\
\text { structure model. } \\
\text { 5. The attractive shape of the } \\
\text { crystal structure model. }\end{array}$ \\
\hline 4. & Innovation & $\begin{array}{l}\text { 1. Creativity and innovation as a } \\
\text { medium for learning physics. } \\
\text { 2. Ease of forming and dismantling } \\
\text { the crystal structure model. } \\
\text { 3. The affordability of the crystal } \\
\text { structure model to a large } \\
\text { number of students. } \\
\text { 4. The use of the crystal structure } \\
\text { model as an innovation in } \\
\text { learning media for physics. } \\
\text { 5. Ability to provide feedback } \\
\text { opportunities to students. }\end{array}$ \\
\hline
\end{tabular}

After obtaining the feasibility test data for crystal structure modeling as an innovative physics learning medium, the next step is to analyze the feasibility data. The analysis technique used to analyze the feasibility of modeling the crystal structure is using the ideal mean equation $\left(\overline{\mathrm{X}}_{1}\right)$ and the ideal standard deviation $\left(\mathrm{SD}_{\mathrm{i}}\right)$ which is shown in equations (1) and (2) below.

$$
\begin{aligned}
& \left.\overline{\mathrm{X}}_{1}=\frac{1}{2} \text { (ideal maximum score }+ \text { ideal minimum score }\right) \\
& \left.\mathrm{SD}_{\mathrm{i}}=\frac{1}{6} \text { (ideal maximum score }- \text { ideal minimum score }\right)
\end{aligned}
$$

Based on equations (1) and (2), the ideal maximum score can be obtained by multiplying the number of items of the indicator by the highest score. The ideal minimum score is obtained by multiplying the number of items of the indicator by the lowest score. The next step is to convert the score into a value with the eligibility criteria which is shown in Table 2.

Table 2. Feasibility Criteria for Crystal Structure Modelling

\begin{tabular}{|c|c|c|}
\hline Assessor Score & $\begin{array}{c}\text { Feasibility } \\
\text { Criteria }\end{array}$ & Category \\
\hline $\mathrm{X} \geq \overline{\mathrm{X}}_{1}+1,0 \mathrm{SB}_{\mathrm{i}}$ & $\mathrm{X} \geq 66,67$ & $\begin{array}{c}\text { Very } \\
\text { Feasible }\end{array}$ \\
\hline$\overline{\mathrm{X}}_{1}<X \leq \overline{\mathrm{X}}_{1}+1,0 \mathrm{SB}_{\mathrm{i}}$ & $50<X \leq 66,67$ & Feasible \\
\hline$\overline{\mathrm{X}}_{1}-1,0 \mathrm{SB}_{\mathrm{i}}<X \leq \overline{\mathrm{X}}_{1}$ & $33,33<X \leq 50$ & $\begin{array}{c}\text { Not } \\
\text { Feasible }\end{array}$ \\
\hline $\mathrm{X} \leq \overline{\mathrm{X}}_{1}-1,0 \mathrm{SB}_{\mathrm{i}}$ & $\mathrm{X} \leq 33,33$ & $\begin{array}{c}\text { Very Not } \\
\text { Feasible }\end{array}$ \\
\hline
\end{tabular}

Based on Table 2, it shows that (X) is the value of each feasibility aspect of modeling the crystal structure of carbon tetrachloride, diamond, and fullerenes as an innovative physics learning medium [19].

\section{Results and Discussion}

The first research result is to develop a crystal structure design for carbon tetrachloride, diamond, and fullerenes which can be shown in Figure 1. The design of these three crystal structures was developed based on references from several relevant reference sources who often conduct research using the three crystals. Some of the reference sources used in this research are still lacking and related. The shortcomings and limitations contained in the crystal structure modeling carried out by previous researchers include the use of complicated and difficult to obtain equipment so that it is difficult to construct by students [20]. Modeling is also carried out with the assistance of computational software. Even though the results are more interesting, the modeling cannot improve the motor skills and creativity of students [21]. Thus, this crystal structure modeling is a development innovation from previous crystal structure modeling. Improvements were made not only in the specifications of the equipment used but also in the type of crystal structure being modelled. 
After that, the results of further research were to construct the modeling of the crystal structure of carbon tetrachloride, diamond, and fullerenes assisted by molymod. The modeling of the crystal structure of carbon tetrachloride, diamond, and fullerenes assisted by molymod as an innovative physics learning medium can be shown in Figure 2.
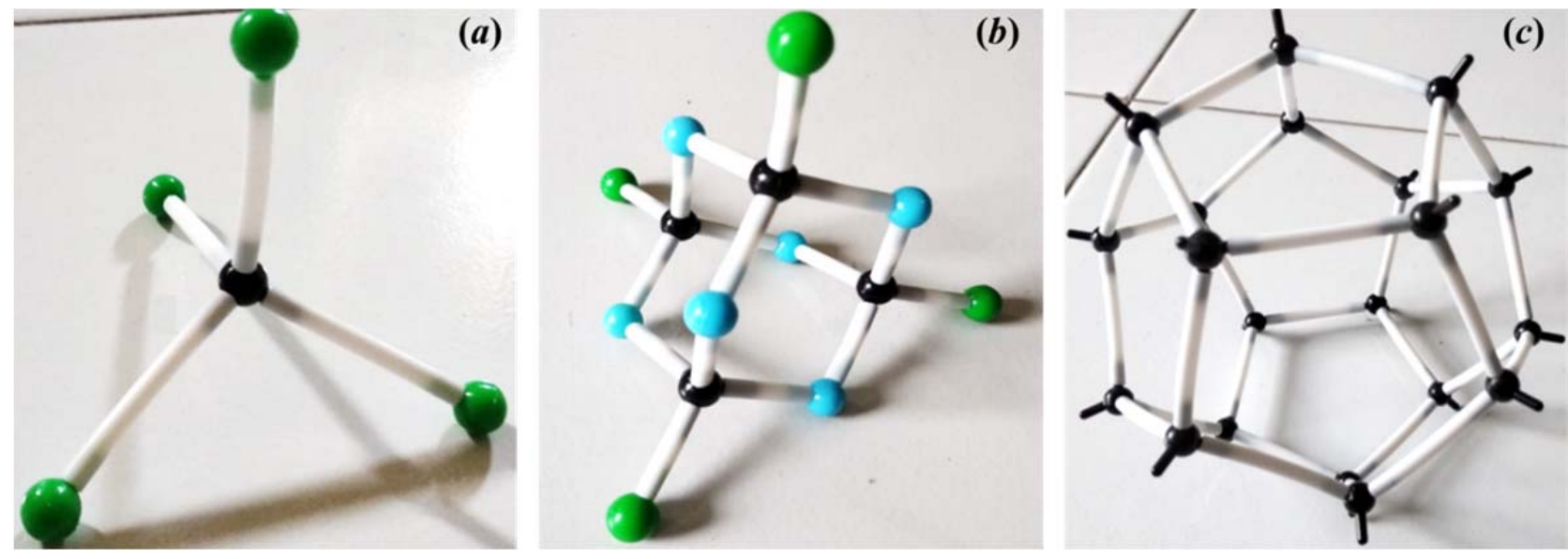

Figure 2. Molymod-assisted crystal structure modelling, (a) carbon tetrachloride, (b) diamond, and (c) fullerenes

Based on Figure 2, it can be observed that in general, the crystal structure models of carbon tetrachloride, diamond, and fullerenes constructed with the help of molymod have the same shape as the crystal structure design shown in Figure 1. In Figure 2 it can be shown that molymod is assembled to form the three. The previously described crystal structure consisting of spherical molymods connected by a cylinder. The spherical molymod acts like an atom while the cylindrical molymod acts as a bond in the crystal structure [22]. Molymod which is spherical has a different colour from one another. This aims to distinguish between the atoms that act as the central or targeted atoms and the atoms that are attached to the central atom or the nearest atom. As shown in Figure 1(a) which is a modeling of the crystal structure of carbon tetrachloride. In Figure 1(a), the sphere molymod used consists of two colours, namely black and green. This is done because the black molymod shows the carbon atom which acts as the central atom. While the green molymod shows the chloride atom which acts like an atom attached to the central atom. The green colour molymod used in Figure 1(a) consists of four because there are four chloride atoms bonded to carbon. This also agrees with the chemical formula for carbon tetrachloride which is $\mathrm{C}^{4+}+\mathrm{Cl}^{-} \rightarrow \mathrm{CCl}_{4}$.

Furthermore, carbon tetrachloride crystals are one of the compounds that have hepatotoxic and nephrotoxin properties. This means that carbon tetrachloride crystals are toxic or poison that attacks the liver and kidneys. These crystals attack the liver and kidneys by producing oxidative stress on the kidneys through lipid and protein peroxidation [23]. Figure 1(b) which is a diamond crystal structure modeling, shows that the molymod sphere used consists of three colors, namely black, blue, and green. However, based on a design that has been developed by the theory, it shows that the crystal structure of a diamond consists only of carbon atoms which are denoted in black. This is because in this research the amount of molymod provided is limited, so the researchers tricked it so that a diamond crystal structure model could be formed using green and blue spherical molymods. Therefore, this can be one of the limitations or drawbacks of this research that the spherical molymod used is limited.

In Figure 1(b) all molymod spheres act as the central atom and the atoms are attached to the central atom. This is due to the crystal structure of the diamond which consists of hard pure carbon bonds [24]. The sphere molymods used in Figure 1(b) are thirteen because four carbon atoms are bonded to each other. This also agrees with the chemical formula for a diamond, which is C. Furthermore, a diamond has a crystal structure which is a cubic arrangement of atoms, just as it is cubic, octahedral, and hexahedral. Diamonds are also one of the most valuable gemstones in the world, because of their beautiful luster and are the hardest gemstones in the world [25]. In the world of physics education, diamonds play an important role in the development of physics, especially in the field of optics. This is because diamonds are used to scratch the grating in a diffraction grating experiment [26].

Furthermore, in Figure 1(c) which is a modeling of the fullerene's crystal structure using black molymods consisting of twenty pieces. However, based on the design that has been developed by the theory, it shows that the crystal structure of fullerenes consists of sixty carbon atoms represented by black. This indicates that the number of carbon atoms modeled in Figure 1(c) is still less than sixty. This is because in this research the amount of 
molymod provided is limited, so the researchers tricked it so that the fullerenes crystal structure model could still be formed using the available molymods so that the fullerene crystal structure is composed of pentahedral carbon bonds. In theory, the fullerene crystal structure is composed of pentahedral and hexahedral carbon bonds [27]. Therefore, this can be a limitation or a drawback in this research that the spherical molymod used is limited.

In Figure 1(c) all molymod spheres act as the central atom and the atoms are attached to the central atom. This is the same for the crystal structure of diamonds. This is because diamond and fullerenes crystals are composed of bonds between carbons, fullerenes are composed of bonds of sixty carbon atoms [28]. The spherical molymods are used in Figure 1(c) number twenty, but there should be sixty of them because there are sixty carbon atoms that are bonded to one another. This is also by the chemical formula for a diamond which is $\left(C_{60}\right)$. In general, fullerenes are insulators, but if the alkali metal is incorporated into fullerenes, at room temperature this material will act as metal. Fullerenes are magnets at high temperatures and pressures [29]. Fullerene crystals can also be used to develop solar cells with higher efficiency than poly-silicon solar cells. Fullerenes also have the potential to be used in fuel cell development or as electrical energy generation from chemical reactions between hydrogen and oxygen gas. In fuel cell batteries, the use of fullerenes is expected to produce fuel cells in small sizes [30]. Thus, it can be concluded that fullerenes crystals have enormous benefits for human life, one of which is the development of environmentally friendly and sustainable renewable energy sources.

Furthermore, the three crystal structures that had been developed were then assessed for their feasibility by six experts. The purpose of this feasibility assessment is to determine how feasible molymod-assisted crystal structure modeling is used as a medium for learning physics in secondary schools. The results of the feasibility assessment of the three crystal structures are shown in Table 3.

Table 3. Feasibility Results of Crystal Structure Modelling

\begin{tabular}{|c|c|c|c|}
\hline No. & Aspect & $\begin{array}{c}\text { Aspect } \\
\text { Value }\end{array}$ & Category \\
\hline 1. & Learning & 98.76 & Very Feasible \\
\hline 2. & Materials & 97.57 & Very Feasible \\
\hline 3. & Display & 87.85 & Very Feasible \\
\hline 4. & Innovation & 90.58 & Very Feasible \\
\hline \multicolumn{2}{|c|}{ Average } & 93.19 & Very Feasible \\
\hline
\end{tabular}

Based on Table 3, it shows that overall that the molymod-assisted crystal structure modeling is very feasible to be used as an innovative physics learning medium. This is supported by the acquisition of an overall feasibility value of 93.19 or almost $100 \%$. However, there are several aspects of assessment that have different values such as aspects of appearance and innovation which receive the least assessment than aspects of learning and material. This is due to the process of assessing the feasibility of modeling the molymod-assisted crystal structure, the six assessors are of the view that the three crystal structures modeled with the help of molymod are less innovative. They argue that crystal structure modeling is more innovative if it is modelled by utilizing existing technological advances so that students also further improve their technological literacy and digital literacy skills. This is also by research which shows that modeling the crystal structure of cellulose with the help of spreadsheets will produce attractive and interactive visualization of images [31]. Other studies have also revealed that visualizing crystal structures using a blender software can produce a movable three-dimensional visualization of crystal structures, making it more interactive and communicative which can increase students' interest in learning it [32]. The opinions expressed by the six assessors are in principle correct, but the purpose of this crystal structure modeling is to improve the psychomotor abilities and creativity of students.

Modeling rocky crystal structures also have disadvantages such as requiring a complex programming language and requiring equipment that is difficult to reach for students in remote areas [33]. Therefore, the modeling of the crystal structure used is assisted by molymod which can be assembled into other crystal structures so that it supports the achievement of psychomotor abilities, creativity, and is easily accessible to students in remote areas. Furthermore, the results of the feasibility assessment on the aspect of the appearance of the three crystal structures modelled with the help of molymod also obtained a small value of 87.85 . This is due to the process of assessing the feasibility of modeling the molymod-assisted crystal structure, the six assessors have the view that the appearance of the three crystal structures modelled with the help of molymod is less attractive. They argue that the third model of the crystal structure with the help of the molymod is less flexible or symmetrical so that the appearance looks less sturdy. This is also by the results of research which reveals that a physics learning media should be developed as attractive as possible [34]. This is done so that the developed learning media can be a fun learning tool for students and can increase students' interest in learning difficult student material such as physics. 
Besides, the six evaluators also argued that the crystal structure of carbon tetrachloride and fullerenes which were modelled with the help of molymod was not by the development design that referred to the appropriate theory. They put forward their argument that the model of the crystal structure of carbon tetrachloride constructed with molymod, in general, has the same structure as the design shown in Figure 1(b), but when viewed closely the colour of the spherical molymode shows different carbon atoms. This is a limitation in this research that the black spherical molymod indicates a limited carbon atom. Therefore, it was tricked by using round molymods that were green and blue to keep the carbon tetrachloride crystal structure formed. This also occurs when modeling the fullerene crystal structure consisting of sixty carbon atoms. The six evaluators of the feasibility of crystal structure put forward their arguments that the fullerenes crystal structure model constructed with molymod structure is less like the design shown in Figure 1(c). When viewed carefully the carbon bonds that form the fullerenes crystal structure in Figure 1(c) consist of pentahedral and hexahedral bonds. However, the fullerenes crystal structure modelled in this research is only formed from pentahedral carbon bonds as shown in Figure 2(c). It is also a limitation in this research that the spherical molymod is black which indicates a limited carbon atom. Therefore, it was done by modelling the crystal structure of fullerenes which are composed of pentahedral carbon bonds.

The modeling of the crystal structure of carbon tetrachloride, diamond, and fullerenes assisted by molymod can be used as an alternative to innovative physics learning media for high school or college students, especially on the topic of crystals and their characteristics. By using the modeling of these three crystal structures, students can be helped in understanding and applying directly the basic concepts of atomic bonds in a crystal, the smallest form of a crystal, and various forms of crystal structures. Moreover, the modeling of the three crystal structures with the help of molymod can be assembled by the students, so that they can model other crystal structures according to their understanding of the concept and creativity. This is supported by the statement of Arista and Kuswanto that physics modelling or physics teaching aids used as a physics learning medium can improve students' understanding of concepts and creativity [35]. Thus, so that physics learning activities are more interactive and so that students interpret the learning they are doing, the teacher should direct students to apply the physics concepts they have learned into direct life, one of which is through modeling the physics concept of the crystal structure. Besides, through modeling the three crystal structures, the teacher can also increase the creativity of students by asking them to construct other crystal structure models with various shapes which are of course based on existing theories and designs.

\section{Conclusion}

The modeling of the crystal structure of carbon tetrachloride, diamond, and fullerenes is designed and constructed using simple, inexpensive, and easily accessible equipment for middle schools or colleges in remote areas, one of which uses molymod. The results of modeling the three crystal structures are generally the same as the design that refers to the theory shown in Figure 1. However, the modeling of the three crystal structures in this research has several limitations, namely the lack of availability of uniformly colored spherical molymods, such as black spherical molymods which are not available. adequate. As a result, some of the carbon atoms in the crystal structure of a diamond are modelled using a non-uniform colored spherical molymod, which should be all black, but also uses blue and green colors. This also happens when modeling the crystal structure of fullerenes. Fullerene's crystals are spherical in the form of pentahedral and hexahedral carbon bonds, but due to the limited black spherical molymod which is a manifestation of carbon atoms, the fullerenes crystal structure modeled in this research is only composed of pentahedral carbon bonds. These are limitations and deficiencies in this research which can be corrected by future researchers. Future researchers can also use molymod to model other crystal structures with more complex atomic bonds. Besides, the modeling of the three crystal structures supported by molymods is also suitable for use as an innovative physics learning medium. This is evidenced by the results of the feasibility assessment of the three molymod-assisted crystal structure models conducted by experts to obtain decent results. Through the media of physics learning using molymod-assisted crystal structure models, it is hoped that students' understanding of the concept and creativity of the crystal structure material and its characteristics will increase. 


\section{References}

[1]. Amazeen, P. G. (2018). From physics to social interactions: Scientific unification via dynamics. Cognitive Systems Research, 52, 640-657.

[2]. Gunawan, G., Harjono, A., Hermansyah, H., \& Herayanti, L. (2019). Guided Inquiry Model Through Virtual Laboratory to Enhance Students'science Process Skills On Heat Concept. Jurnal Cakrawala Pendidikan, 38(2), 259-268.

[3]. Kaur, T., Blair, D., Moschilla, J., Stannard, W., \& Zadnik, M. (2017). Teaching Einsteinian physics at schools: part 1, models and analogies for relativity. Physics Education, 52(6), 065012.

[4]. Scott, K., Rowe, F., \& Pollock, V. (2018). Creating the good life? A wellbeing perspective on cultural value in rural development. Journal of Rural Studies, 59, 173-182.

[5]. Hartini, S., Firdausi, S., Misbah, M., \& Sulaeman, N. F. (2018). The development of physics teaching materials based on local wisdom to train saraba kawa character. Jurnal Pendidikan IPA Indonesia, 7(2), $130-137$.

[6]. Istiningrum, R. B., \& Wiyantoko, B. (2017). Improvement of Learning Outcomes Inorganic Chemistry Through Cooperative Learning Approach Types Student TeamsAchievement Divisions with The Help Of Molymod Props. International Journal of Chemistry Education Research, 1(1), 13-23.

[7]. Marpaung, D. N., Siregar, L. F., \& Pongkendek, J. J. (2020, July). Effect of using chemsketch on teaching molecular shape of hydrocarbon to increase student's achievement. In Journal of Physics: Conference Series (Vol. 1569, No. 4, p. 042101). IOP Publishing.

[8]. Wood, E. J., \& Gray, B. J. (1980). A class practical using space-filling models (Molymods). Biochemical Education, 8(4), 102-103.

[9]. Toon, A. (2011). Playing with molecules. Studies in History and Philosophy of Science Part A, 42(4), 580-589.

[10]. Young, D. D., \& Schultz, P. G. (2018). Playing with the molecules of life. ACS chemical biology, 13(4), 854-870.

[11]. Sausan, I., Saputro, S., \& Indriyanti, N. Y. (2020). A New Chemistry Multimedia: How Can It Help Junior High School Students Create a Good Impression. International Journal of Instruction, 13(4), 457-476.

[12]. Scalfani, V. F., \& Vaid, T. P. (2014). 3D printed molecules and extended solid models for teaching symmetry and point groups. Journal of Chemical Education, 91(8), 1174-1180.

[13]. Georgakilas, V., Perman, J. A., Tucek, J., \& Zboril, R. (2015). Broad family of carbon nanoallotropes: classification, chemistry, and applications of fullerenes, carbon dots, nanotubes, graphene, nanodiamonds, and combined superstructures. Chemical reviews, 115(11), 47444822.

[14]. Nasir, S., Hussein, M. Z., Zainal, Z., \& Yusof, N. A. (2018). Carbon-based nanomaterials/allotropes: A glimpse of their synthesis, properties and some applications. Materials, 11(2), 295.
[15]. Wu, H., \& Feng, Q. (2017). Fabrication of bimetallic $\mathrm{Ag} / \mathrm{Fe}$ immobilized on modified biochar for removal of carbon tetrachloride. Journal of Environmental Sciences, 54, 346-357.

[16]. Shang, S., Tong, Y., Wang, Y., \& Huang, F. (2020). Analysis crystal characteristics of diamond synthesized by different dynamic loading methods. The International Journal of Multiphysics, 14(1), 81-96.

[17]. Wang, B., Zheng, S., Saha, A., Bao, L., Lu, X., \& Guldi, D. M. (2017). Understanding charge-transfer characteristics in crystalline nanosheets of fullerene/(metallo) porphyrin cocrystals. Journal of the American Chemical Society, 139(30), 1057810584.

[18]. Del Castillo, R. M., Miralrio, A., Rios, C., \& Salcedo, R. (2019). Organometallic complexes of carbon nanotori. Journal of molecular modeling, 25(8), 1-13.

[19]. Susanti, N., Yennita, Y., \& Azhar, A. (2020). Development of Contextual Based Electronic Global Warming Modules Using Flipbook Applications as Physics Learning Media in High Schools. Journal of Educational Sciences, 4(3), 541-559.

[20]. Priyambodo, E., \& Wulaningrum, S. (2017). Using Chemistry Teaching Aids Based Local Wisdom as an Alternative Media for Chemistry Teaching and Learning. International Journal of Evaluation and Research in Education, 6(4), 295-298.

[21]. Svyetlichnyy, D. S., Perig, A. V., Lach, Ł., Straka, R., \& Svyetlichnyy, A. (2019). Edification in creation of Lattice Boltzmann models for materials science students. International Journal of Continuing Engineering Education and Life Long Learning, 29(3), 151-181.

[22]. Safitri, N. Y., \& Dwiningsih, K. (2020). Development Interactive Multimedia Using 3D Virtual Modelling on Intermolecular Forces Matter. International Journal of Chemistry Education Research, 4(1), 17-25.

[23]. Flampouri, E., Sotiropoulou, N. S. D., Mavrikou, S., Mouzaki-Paxinou, A. C., Tarantilis, P. A., \& Kintzios, S. (2017). Conductive polymer-based bioelectrochemical assembly for in vitro cytotoxicity evaluation: Renoprotective assessment of Salvia officinalis against carbon tetrachloride induced nephrotoxicity. Biochimica et Biophysica Acta (BBA)-General Subjects, 1861(9), 2304-2314.

[24]. Ding, J. C., Dai, W., Zhang, T. F., Zhao, P., Yun, J. M., Kim, K. H., \& Wang, Q. M. (2018). Microstructure and properties of $\mathrm{Nb}$-doped diamondlike carbon films deposited by high power impulse magnetron sputtering. Thin solid films, 663, 159-167.

[25]. Shekhar, M., \& Yadav, S. K. S. (2020). Diamond abrasive based cutting tool for processing of advanced engineering materials: a review. Materials Today: Proceedings, 22, 3126-3135.

[26]. Zhang, B., Wang, Q., Shen, N., \& Ding, H. (2017). Experimental investigation and numerical analysis of mechanical ruling for an Aluminum-Coated Diffraction Grating. Journal of Manufacturing Science and Engineering, 139(2). 
[27]. Zheng, S., Cuong, N. T., Okada, S., Xu, T., Shen, W., Lu, X., \& Tsukagoshi, K. (2018). Solventmediated shape engineering of fullerene $\left(\mathrm{C}_{60}\right)$ polyhedral microcrystals. Chemistry of Materials, 30(20), 7146-7153.

[28]. Auvert, G., \& Auvert, M. (2020). Single Covalent Bonding Structure in Fullerenes, Carbon Nanotubes and Closed Nanotubes. Open Journal of Physical Chemistry, 10(3), 183-195.

[29]. Berezkin, V. I., Kidalov, S. V., Popov, V. V., \& Sharenkova, N. V. (2020). Magnetic properties of C60/exfoliated graphite carbon system. Fullerenes, Nanotubes and Carbon Nanostructures, 28(2), 150153.

[30]. Coro, J., Suárez, M., Silva, L. S., Eguiluz, K. I., \& Salazar-Banda, G. R. (2016). Fullerene applications in fuel cells: A review. International Journal of Hydrogen Energy, 41(40), 17944-17959.

[31]. Duchemin, B. (2017). Size, shape, orientation and crystallinity of cellulose I $\beta$ by X-ray powder diffraction using a free spreadsheet program. Cellulose, 24(7), 2727-2741.
[32]. Mills, M. J., Sale, K. L., Simmons, B. A., \& Popelier, P. L. (2017). Rhorix: An interface between quantum chemical topology and the 3D graphics program blender. Journal of computational chemistry, 38(29), 2538-2552.

[33]. Shatri, Z. G. (2020). Advantages and Disadvantages of Using Information Technology in Learning Process of Students. Journal of Turkish Science Education, 17(3), 420-428.

[34]. Kurniawan, R. B., Mujasam, M., Yusuf, I., \& Widyaningsih, S. W. (2019, February). Development of physics learning media based on Lectora Inspire Software on the elasticity and Hooke's law material in senior high school. In Journal of Physics: Conference Series (Vol. 1157, No. 3, p. 032022). IOP Publishing.

[35]. Arista, F. S., \& Kuswanto, H. (2018). Virtual Physics Laboratory Application Based on the Android Smartphone to Improve Learning Independence and Conceptual Understanding. International Journal of Instruction, 11(1), 1-16. 